\title{
Corrigenda
}

Genome Research 26: 291-300 (2016)

\section{Corrigendum: Model-based analyses of whole-genome data reveal a complex evolutionary history involving archaic introgression in Central African Pygmies}

PingHsun Hsieh, August E. Woerner, Jeffrey D. Wall, Joseph Lachance, Sarah A. Tishkoff, Ryan N. Gutenkunst, and Michael F. Hammer

The authors would like to correct the omission of the term "model-based" in the Abstract. The corrected sentence should read as follows:

"our inference method rejects the hypothesis that the ancestors of AMH were genetically isolated in Africa, thus providing model-based whole genome-level evidence of African archaic admixture."

In addition, they also would like to make a change in the last sentence in the Introduction, and the corrected sentence should read as follows:

"Together, our results provide a model-based whole-genome perspective on archaic introgression in Africa."

The article has already been corrected in both the PDF and full-text HTML files online.

doi: $10.1101 /$ gr.206524.116

Genome Research 25: 814-824 (2015)

\section{Corrigendum: Frequent somatic transfer of mitochondrial DNA into the nuclear genome} of human cancer cells

Young Seok Ju, Jose M.C. Tubio, William Mifsud, Beiyuan Fu, Helen R. Davies, Manasa Ramakrishna, Yilong Li, Lucy Yates, Gunes Gundem, Patrick S. Tarpey, Sam Behjati, Elli Papaemmanuil, Sancha Martin, Anthony Fullam, Moritz Gerstung, ICGC Prostate Cancer Working Group, ICGC Bone Cancer Working Group, ICGC Breast Cancer Working Group, Jyoti Nangalia, Anthony R. Green, Carlos Caldas, Åke Borg, Andrew Tutt, Ming Ta Michael Lee, Laura J. van't Veer, Benita K.T. Tan, Samuel Aparicio, Paul N. Span, John W.M. Martens, Stian Knappskog, Anne Vincent-Salomon, Anne-Lise Børresen-Dale, Jórunn Erla Eyfjörd, Ola Myklebost, Adrienne M. Flanagan, Christopher Foster, David E. Neal, Colin Cooper, Rosalind Eeles, G. Steven Bova, Sunil R. Lakhani, Christine Desmedt, Gilles Thomas, Andrea L. Richardson, Colin A. Purdie, Alastair M. Thompson, Ultan McDermott, Fengtang Yang, Serena Nik-Zainal, Peter J. Campbell, and Michael R. Stratton

The names of two co-authors, Ola Myklebost and G. Steven Bova, were omitted from the authorship list of this article. Please note the corrected list above. The author and affiliation lists have already been corrected in both the PDF and full-text HTML files online. 


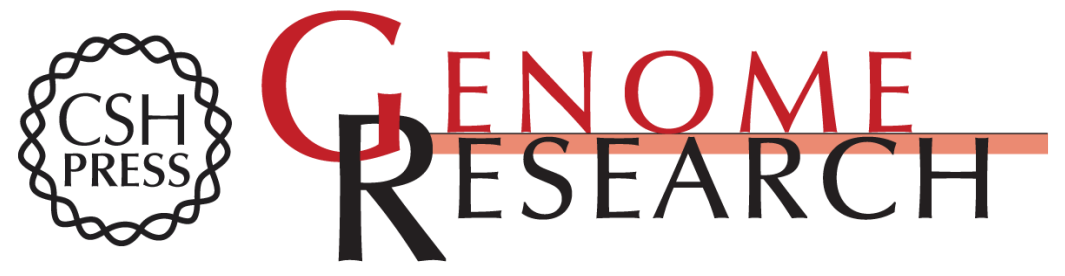

\section{Corrigendum: Frequent somatic transfer of mitochondrial DNA into the nuclear genome of human cancer cells}

Young Seok Ju, Jose M.C. Tubio, William Mifsud, et al.

Genome Res. 2016 26: 717.2

Access the most recent version at doi:10.1101/gr.206557.116

Related Content Frequent somatic transfer of mitochondrial DNA into the nuclear genome of human cancer cells

Young Seok Ju, Jose M.C. Tubio, William Mifsud, et al.

Genome Res. June , 2015 25: 814-824

Open Access Freely available online through the Genome Research Open Access option.

\section{License}

Email Alerting Receive free email alerts when new articles cite this article - sign up in the box at the Service top right corner of the article or click here.

\section{Affordable, Accurate Sequencing.}

To subscribe to Genome Research go to:

https://genome.cshlp.org/subscriptions 